\title{
SISTEM PAKAR PENENTUAN MOTIF DAN WARNA BATIK BERDASARKAN CIRI FISIK DENGAN METODE FORWARD CHAINING
}

\author{
${ }^{[1]}$ Riska Dhenabayu, ${ }^{[2]}$ Hesty Puspita Sari, dan ${ }^{[3]}$ Silviana Valyanda Yunita Sari \\ ${ }^{[1]}$ Universitas Islam Balitar, ${ }^{[2]}$ Universitas Islam Balitar, ${ }^{[3]}$ Universitas Islam Balitar
}

\begin{abstract}
Abstrak : Membatik merupakan teknik menghias kain tradisional Indonesia dengan menggunakan lilin untuk membuat pola dan desain. Penggunaan batik antara satu individu dengan individu lainnya memang berbeda, bergantung dari ciri fisik dan karakter pemakai agar terlihat bagus, elegan, dan jragem (berwibawa). Kesesuaian pengguna batik ini merupakan hal yang penting mengingat kebutuhan masyarakat terhadap penampilan yang nyaman, pantas, dan menarik. Ingatan manusia dan ahli yang memahami batik sangatlah terbatas, maka diperlukan sebuah sistem untuk menjaga salah satu warisan budaya ini agar bisa bertahan. Tujuan dari penelitian ini adalah untuk mengembangkan dan menerapkan basis pengetahuan dan sistem pakar yang dapat dengan cepat mencocokan batik yang sesuai dengan ciri fisik pengguna khususnya batik Blitar. Sistem ini akan menarik kesimpulan dari beberapa jenis masukan yang masuk ke sistem berdasarkan warna kulit, ukuran pakaian, usia, dan jenis kelamin. Program ini menggunakan PHP sebagai bahasa pemrograman dan MySQL sebagai basis data sistem.
\end{abstract}

Kata kunci: Batik Blitar, Forward Chaining, Sistem Pakar

Abstract : Batik is a methode of producing colored and designs pattern on textiles by applying liquid wax. The use of batik between one individual and another is different, depends on the physical characteristics and one's features like good looking, ellegant and authoritative (java : jragem). Well suited batik wearing is needed towards the appearance of a comfortable, appropriate and interesting, in other wise the human memory and experts who understand batik well is very limited, so the system can keep one of these cultural heritage to survive. The purpose of this research is to develop and apply the knowledge base and expert system that can quickly match the batik in accordance with the user's physical characteristics, especially batik Blitar. This system concluded several types of inputs on the system based on skin color, clothing size, age, and gender. This program uses PHP as the programming language and MySQL as the system data base.

Keywords: Batik Blitar, Expert System, Forward Chaining.

\section{Pendahuluan}

Batik merupakan warisan budaya Indonesia yang memiliki motif yang beragam dan setiap motif memiliki filosofi tersendiri. Setelah ditetapkan oleh United Nations Educational, Scientific and Cultural Organization (UNESCO) sebagai kebudayaan asli Indonesia, ketertarikan masyarakat terhadap batik semakin meningkat. Hal ini ditandai dengan penggunaan batik dalam berbagai jenis pakaian baik formal maupun nonformal, serta berbagai dekorasi yang mengandung unsur batik. Informasi mengenai keberadaan batik Blitar ada di museum Leiden Belanda dengan nama "Batik Afkomstig Uit Blitar 1902" (Panji, 2014: 6). Namun, batik yang ada saat itu masih sebatas penghias dinding ruangan dengan motif 
binatang dan tumbuhan sebagai simbol yang menggambarkan sindiran bagi para penguasa Belanda yang menjajah Indonesia. Batik Blitar terus mengalami perkembangan. Hingga saat ini, terdapat bermacammacam motif batik Blitar dengan warna yang beragam. Dalam memilih motif dan warna batik, banyak masyarakat yang masih bingung atau belum mengetahui batik seperti apa yang sesuai dengan ciri fisik masing-masing (Asti, Ambar, 2011: 4). Penggunaan batik antara satu individu dengan individu lainnya memang berbeda, bergantung dari ciri fisik dan karakter pemakai agar terlihat bagus, elegan dan jragem (berwibawa). Adakalanya sesorang terlihat kurang cocok memakai batik dengan warna yang cerah dan tajam karena memiliki warna kulit yang gelap, atau orang yang gemuk menjadi terlihat lebih gemuk karena motif yang digunakan berukuran besar (Asti dan Ambar, 2011: 6). Hal ini disebabkan minimnya pengetahuan masyarakat tentang pemilihan batik yang sesuai dengan fisik masing-masing.

Kesesuaian penggunaan batik ini merupakan hal yang penting mengingat kebutuhan masyarakat terhadap penampilan yang nyaman, pantas, dan menarik. Seringkali seseorang yang kurang mengerti tentang fashion terutama dalam pemilihan batik, akan cenderung bertanya pada orang lain untuk meminta pendapat. Jika orang yang dimintai saran memang orang yang tepat tentu tidak akan jadi masalah, tetapi jika orang tersebut hanya asal memberikan saran maka dapat merugikan orang lain. Di Blitar sendiri khususnya, pakar ahli batik masih sangat terbatas. Oleh karena itu, sistem ini dibuat dengan tujuan untuk memudahkan masyarakat dalam memilih jenis batik yang sesuai.

Berdasarkan hal tersebut, peneliti mengangkat permasalahan yang terjadi dalam masyarakat yakni bagaimana cara menerapkan metode Forward Chaining pada perancangan sistem pakar penentuan motif dan warna batik berdasarkan ciri fisik serta melakukan pengujian sistem pakar penentuan motif dan warna batik dengan menggunakan black box testing. Tujuan dari penelitian ini adalah untuk mengetahui cara menerapkan metode Forward Chaining pada perancangan sistem pakar penentuan motif dan warna batik berdasarkan ciri fisik, serta mengetahui hasil pengujian sistem dengan menggunakan black box testing, sehingga dapat diketahui apakah program tersebut sudah sesuai dengan yang diharapkan atau belum.

Pada penelitian sebelumnya yang dilakukan oleh P. Hetty dan Clara (2013) dengan judul "Rule Base Expert System dengan Metode Forward Chaining untuk Memprediksi Kualitas Kain Batik", dihasilkan program sistem pakar untuk membantu memprediksi batik yang berkualitas dari segi bahan kain yang digunakan. Mengingat kebutuhan masyarakat dalam memilih batik tidak hanya berdasarkan kualitas kain saja, peneliti membuat sebuah sistem yang membantu memilihkan batik yang sesuai untuk pengguna berdasarkan ciri fisiknya. Cara kerja program sistem pakar penentuan motif dan warna batik ini adalah dengan memasukan beberapa parameter melalui tanya-jawab antara sistem dengan pengguna seputar ciri fisik pengguna, kemudian sistem akan memberikan kesimpulan dan solusi berdasarkan data yang telah dimasukkan pengguna. Oleh karena itu, metode yang tepat untuk digunakan dalam program sistem pakar ini adalah metode Forward Chaining.

Forward Chaining merupakan suatu proses pencocokan fakta dengan menguji kebenaran hipotesis untuk mendapatkan kesimpulan. Forward Chaining dimulai dari memasukan gejala atau syarat $(I F)$ baru kemudian akan muncul solusi (THEN). Kelebihan utama dari Forward Chaining yaitu metode ini akan bekerja dengan baik ketika problem bermula dari mengumpulkan atau menyatukan informasi kemudian mencari kesimpulan apa yang dapat diambil dari informasi tersebut, selain itu metode ini mampu menyediakan banyak sekali informasi dari hanya jumlah kecil data. 


\section{Perancangan Sistem}

\section{A. Data Flow Diagram (DFD)}

Data Flow Diagram (DFD) adalah suatu diagram yang menggunakan notasi-notasi untuk menggambarkan arus dari data sistem, sehingga diagram ini berguna untuk mendesain sistem yang akan dibuat. DFD dapat dilihat pada gambar 2.1 dan 2.2 berikut ini.

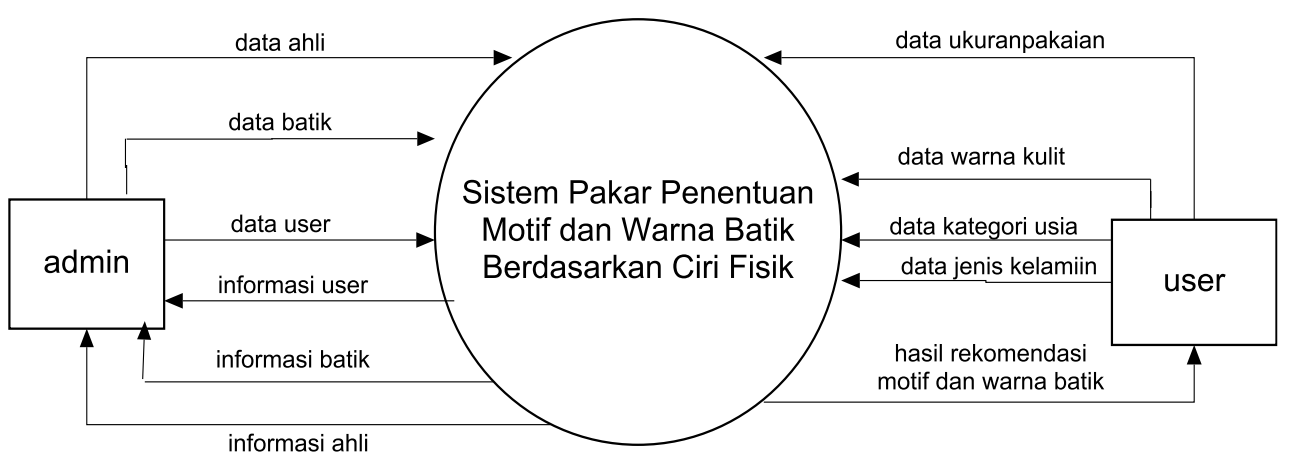

Gambar 2.1 DFD level 0
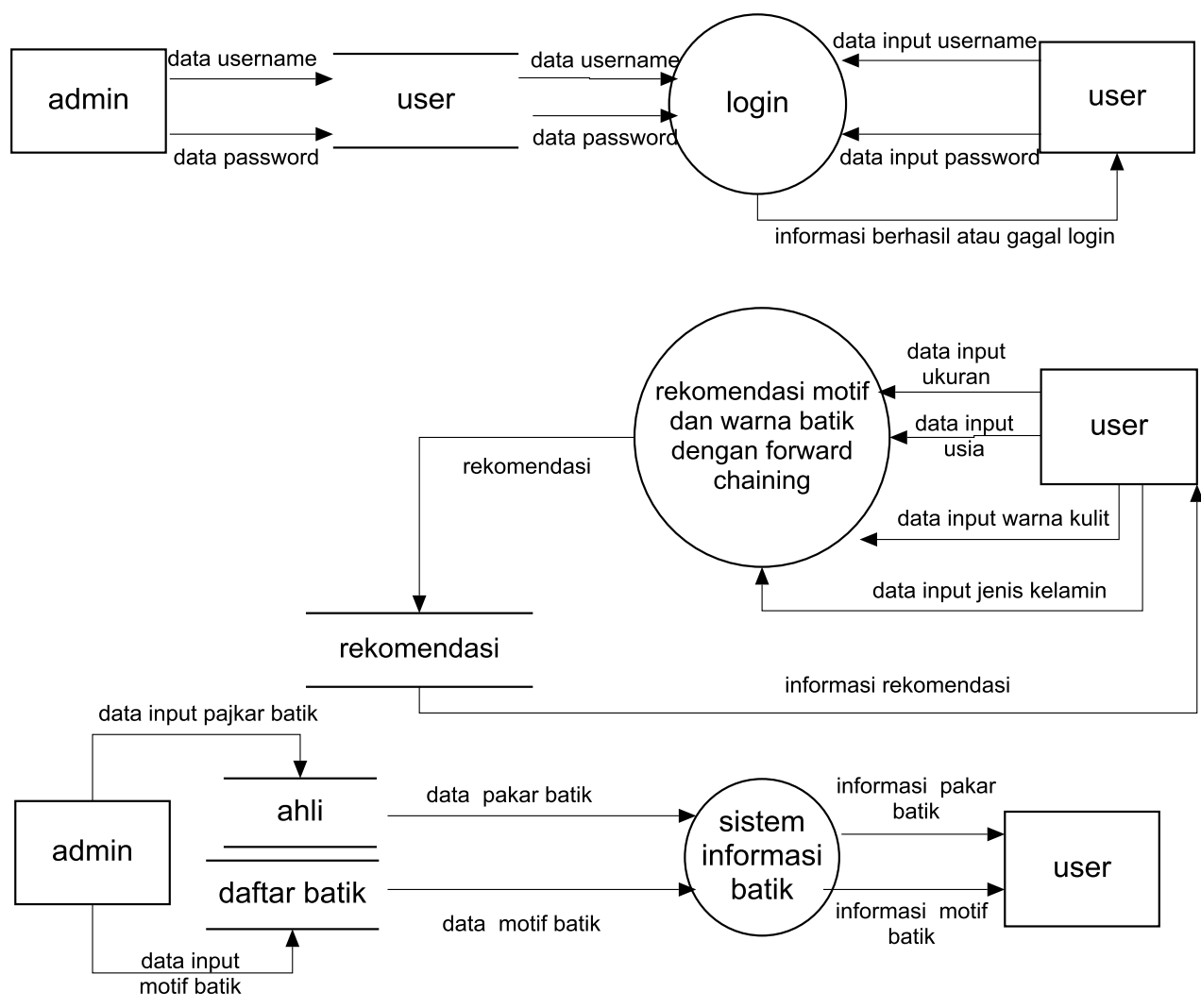

Gambar 2.2 DFD Level 1 


\section{B. Bagan Alir (flowchart) Sistem Pakar Penentuan Motif dan Warna Batik}

Sistem yang dirancang ini menggunakan basis model yang diambil dari model Forward Chaining. Metode ini untuk menentukan hasil rekomendasi motif dan warna batik berdasarkan rule yang telah dibentuk. Adapun alurnya dapat dilihat pada gambar 2.3 berikut ini.

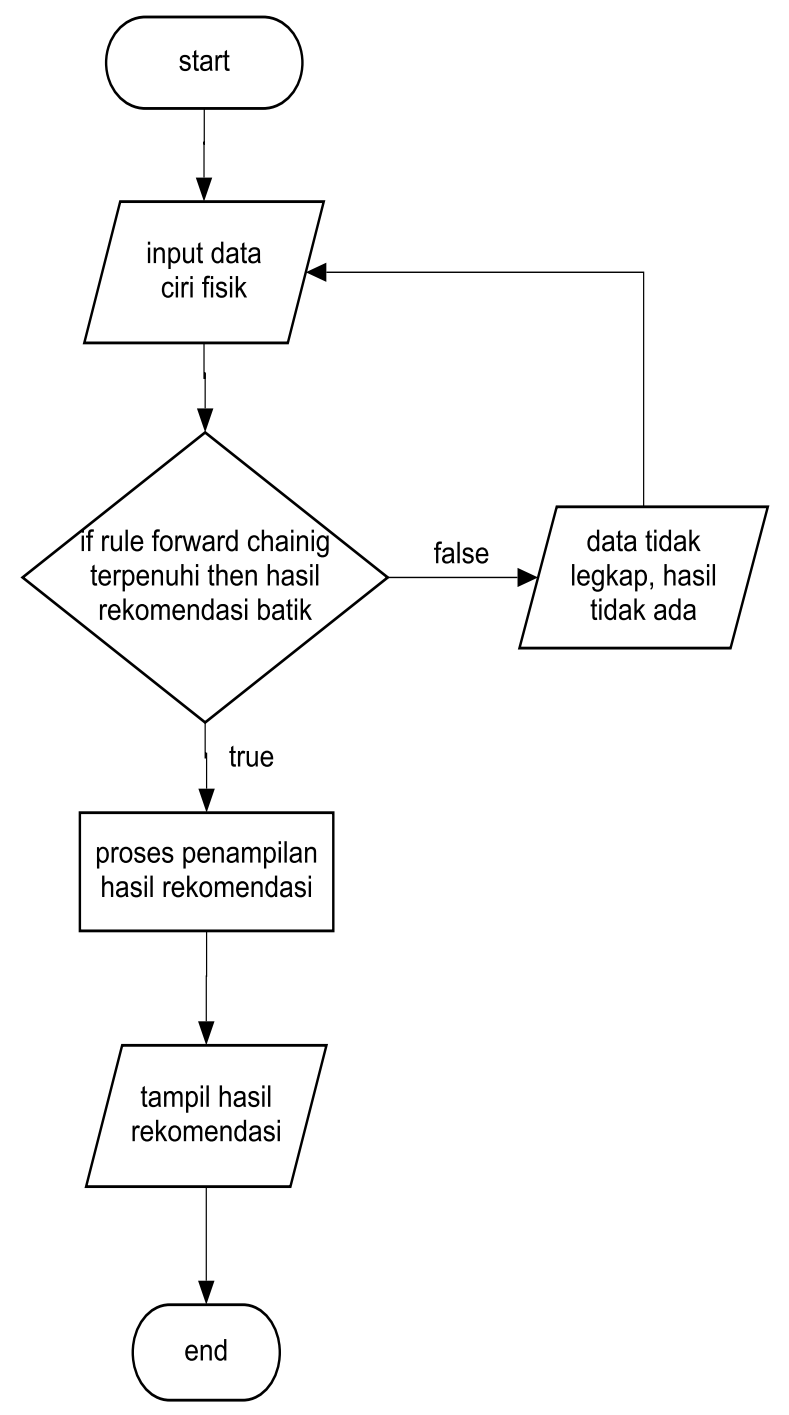

Gambar 2.3 Flowchart metode Forward Chaining

\section{Entity Relationship Diagram (ERD)}

Pada tahap ini dilakukan analisis data-data yang digunakan dalam membangun suatu database agar sistem dapat berjalan sesuai harapan. Data-data yang akan dimasukkan ke sistem saling berrelasi antara data yang satu dengan data yang lainnya. Bentuk ERD dapat dilihat pada Gambar 2.4 berikut ini. 


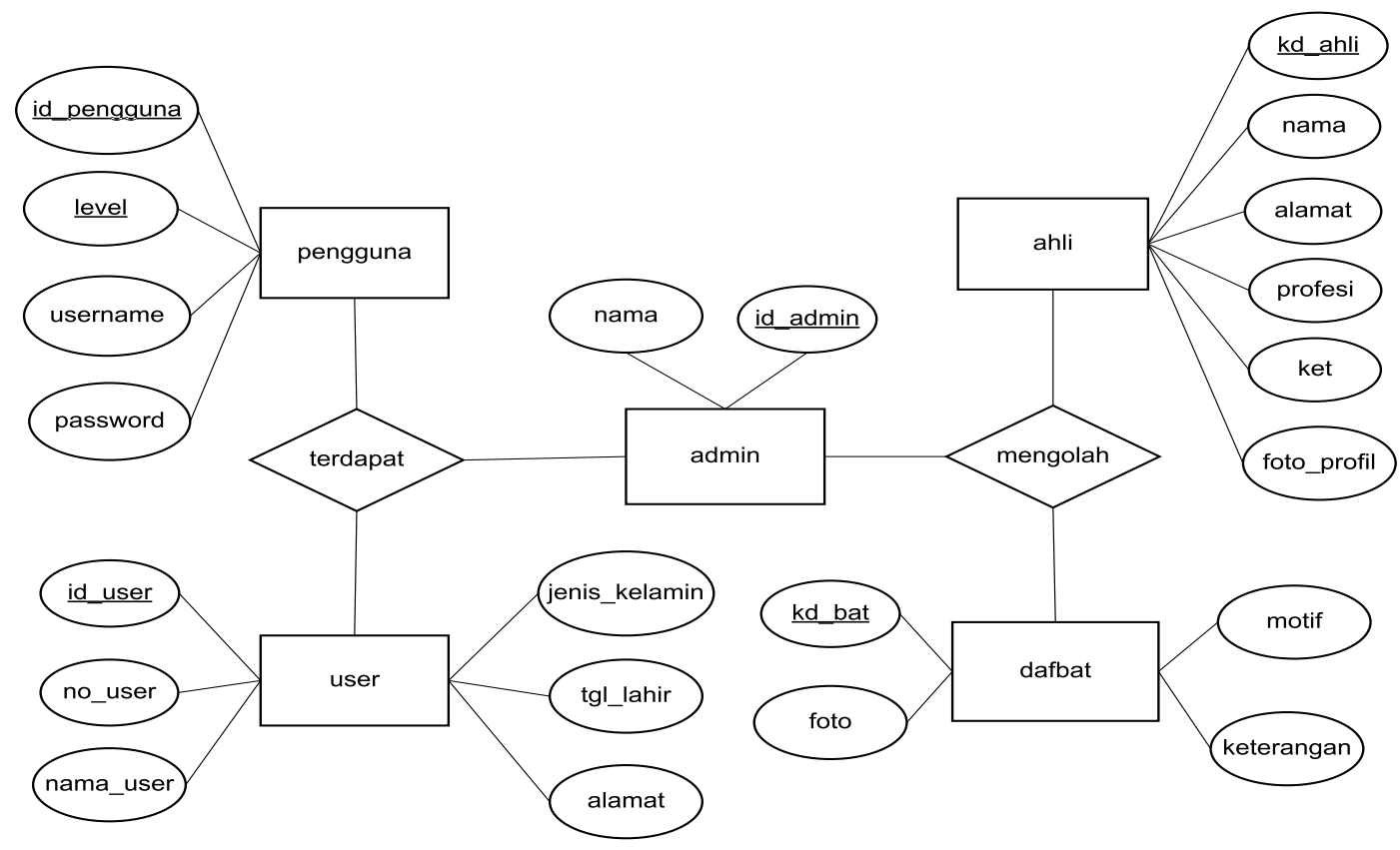

Gambar 2.4 Entity Relationship Diagram (ERD)

\section{Hasil dan Pembahasan}

Pembuatan program sistem pakar penentuan motif dan warna batik ini sesuai dengan perancangan program. Berikut ini tampilan - tampilan halaman program yang dibuat.

\section{A. Halaman Home}

Pada halaman ini terdapat beberapa menu yaitu: (1) menu home di mana terdapat kotak dialog login; (2) menu daftar batik yang berisikan data batik beserta keterangannya; (3) menu ketentuan yang berisi aturan-aturan dalam penggunaan program sistem pakar; (4) menu daftar pakar yang berisi informasi mengenai para pakar; dan (5) menu contact us yang berisi alamat galeri batik Djojo Koesoemo.

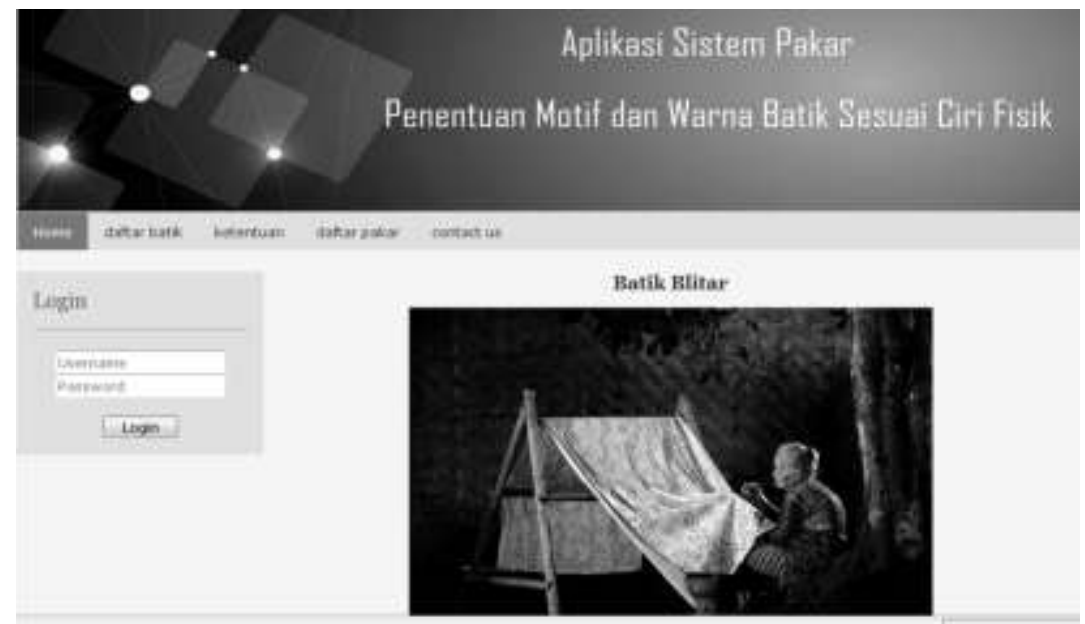

Gambar 3.1 Tampilan Halaman Home 


\section{B. Halaman Konsultasi}

Halaman ini menampilkan halaman konsultasi yang berisi pertanyan-pertanyaan mengenai ciri fisik user, sekaligus halaman rekomendasi. Jawaban dari pertanyaan-pertanyaan tersebut akan menjadi masukkan sistem. Selanjutnnya, masukkan tersebut akan diproses menggunakan metode Forward Chaining yang berbentuk statements If-else dalam kode PHP. Dari proses tersebut akan dihasilkan output berupa motif dan warna batik yang sesuai dengan data yang dimasukkan.
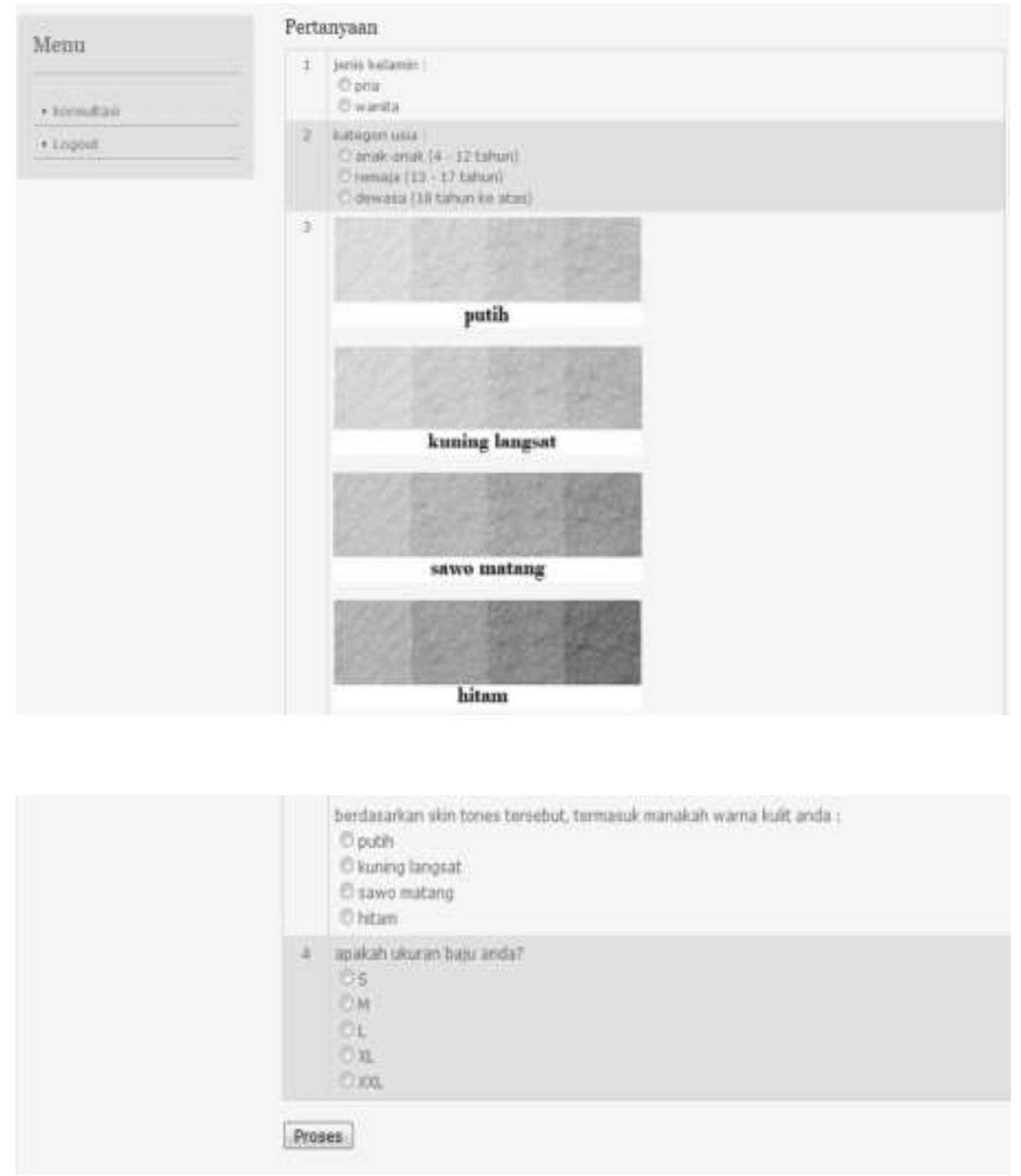

Gambar 3.2 Tampilan Halaman Konsultasi

\section{Halaman Rekomendasi}

Pada halaman Rekomendasi ini terdapat penjelasan sekaligus foto batik yang direkomendasikan oleh sistem seperti berikut. 


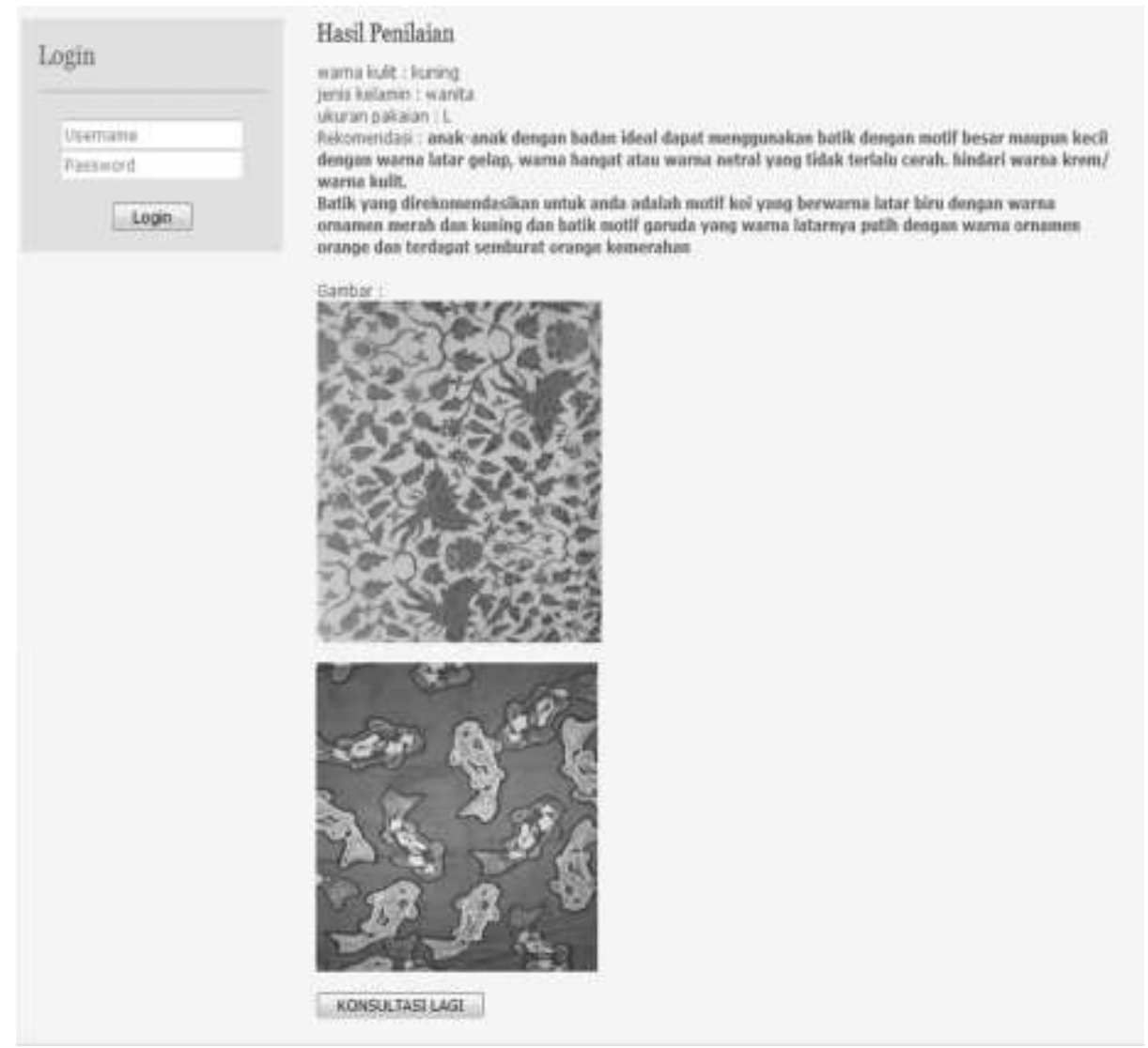

Gambar 3.3 Tampilan Halaman Rekomendasi

\section{Pembahasan dengan Metode Forward Chaining}

Pemilihan motif dan warna batik yang dimaksud dalam penelitian ini menggunakan metode Forward Chaining berdasarkan kriteria yang ditentukan dengan langkah-langkah sebagai berikut.

\section{Menentukan Standar Warna Kulit}

Skala warna kulit yang digunakan berdasarkan Fiitzpatrick Scale di mana pada setiap skala warna terdapat empat tingkatan warna kulit. Fiitzpatrick Scale merupakan skema klasifikasi warna kulit manusia berdasarkan respon berbagai tipe kulit terhadap cahaya ultra violet (UV). Pada tahun 1972 di Briesbane, Australia, Fitzpatrick pertama kali menggolongkan warna kulit ke dalam tiga tipe (tipe I-III) berdasarkan hasil studinya mengenai outdoor sunscreen. Ketiga tipe tersebut dengan mudahnya diterima dan menjadi populer dikalangan dermatologis, sehingga United State Food and Drug Administration (US FDA) menggunakan klasifikasi Fitzpatrick untuk digunakan sebagai evaluasi penilaian sun protection factor (SPF) (Sachdeva, 2009: 93-96). Fitzpatrick kemudian mengembangkan lebih jauh lagi dan saat ini terdapat enam tipe sebagai berikut. 
a. Tipe I : kulit berwarna putih pucat, berbintik (freckled), mudah terbakar, tidak berubah gelap

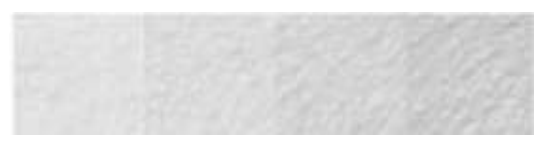

\section{Gambar 3.4 Tipe I}

b. Tipe II : kulit putih cerah, mudah terbakar, bisa berubah menjadi warna gelap minimal

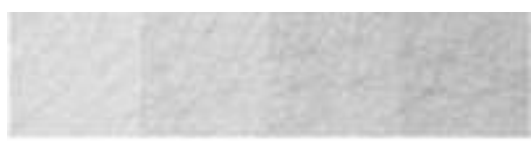

\section{Gambar 3.5 Tipe II}

c. Tipe III : kulit berwarna putih krem/kuning, kadang-kadang terbakar ringan (burn moderately), penggelapan warna kulitnya beragam

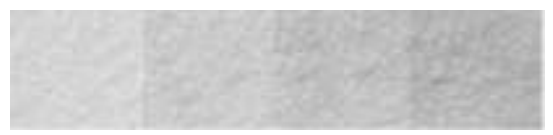

Gambar 3.6 Tipe III

d. Tipe IV : kulit berwarna coklat muda, terbakar minimal (burn minimally), mudah menggelap sampai berwarna coklat sedang

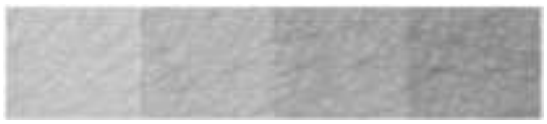

Gambar 3.7 Tipe IV

e. Tipe V : kulit berwarna coklat gelap, jarang terbakar, sangat mudah berubah menjadi gelap

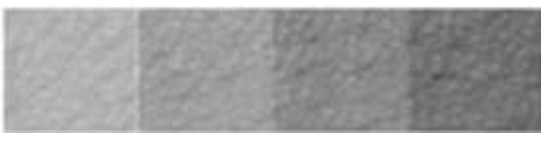

Gambar 3.8 Tipe V

f. Tipe VI : kulit berwarna hitam atau coklat tua cenderung hitam, lebih gelap dibanding tipe V, tidak terbakar, sangat mudah menjadi gelap

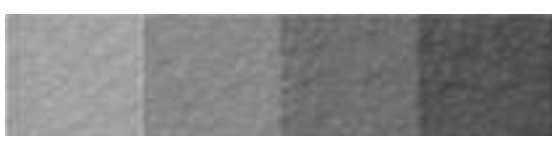

Gambar 3.9 Tipe VI 


\section{Menentukan Standar Ukuran Pakaian}

Standar ukuran pakaian yang digunakan dalam program ini merupakan standar ukuran Internasional (Internastional Standard) berdasarkan ISO/TR 106521991 Standard Sizing System for Clothes. Berikut disajikan tabel standar ukuran pakaian.

Tabel 3.1 Standar Ukuran Pakaian Pria

\begin{tabular}{llllll}
\hline ukuran pria & \multicolumn{5}{c}{ cm } \\
\cline { 2 - 6 } & $\mathrm{S}$ & $\mathrm{M}$ & $\mathrm{L}$ & $\mathrm{XL}$ & $\mathrm{XXL}$ \\
lingkar dada & $96-99$ & $100-103$ & $104-107$ & $108-111$ & $112-115$ \\
lingkar pinggang & $84-87$ & $88-91$ & $92-95$ & $96-99$ & $100-103$ \\
lingkar pinggul & $98-101$ & $102-105$ & $106-109$ & $110-113$ & $114-117$ \\
\hline
\end{tabular}

Tabel 3.2 Standar Ukuran Pakaian Wanita

\begin{tabular}{llllll}
\hline ukuran wanita & \multicolumn{5}{c}{$\mathbf{c m}$} \\
\cline { 2 - 6 } & $\mathrm{S}$ & $\mathrm{M}$ & $\mathrm{L}$ & $\mathrm{XL}$ & $\mathrm{XXL}$ \\
lingkar dada & $84-87$ & $88-92$ & $93-97$ & $98-102$ & $103-107$ \\
lingkar pinggang & $68-71$ & $72-76$ & $77-81$ & $82-86$ & $87-91$ \\
lingkar pinggul & $93-96$ & $97-101$ & $102-106$ & $107-111$ & $112-116$ \\
\hline
\end{tabular}

Tabel 3.3 Standar Ukuran Pakaian Anak Laki-Laki

\begin{tabular}{llllll}
\hline \multicolumn{1}{c}{ ukuran anak } & \multicolumn{5}{c}{$\mathbf{c m}$} \\
\cline { 2 - 6 } \multicolumn{1}{c}{ laki-laki } & $\mathrm{S}$ & $\mathrm{M}$ & $\mathrm{L}$ & $\mathrm{XL}$ & $\mathrm{XXL}$ \\
lingkar dada & $66-69$ & $70-73$ & $74-78$ & $79-83$ & $85-89$ \\
lingkar & $57-59$ & $60-63$ & $64-68$ & $69-73$ & $74-78$ \\
pinggang & & & & & \\
lingkar pinggul & $63-67$ & $68-74$ & $75-82$ & $82-87$ & $88-92$ \\
\hline
\end{tabular}

Tabel 3.4 Standar Ukuran Pakaian Anak Perempuan

\begin{tabular}{llllll}
\hline \multicolumn{1}{c}{ Ukuran anak } & \multicolumn{5}{c}{$\mathbf{c m}$} \\
\cline { 2 - 6 } perempuan & $\mathrm{S}$ & $\mathrm{M}$ & $\mathrm{L}$ & $\mathrm{XL}$ & $\mathrm{XXL}$ \\
Lingkar dada & $62-65$ & $67-71$ & $73-77$ & $79-83$ & $85-89$ \\
Lingkar & $57-59$ & $60-62$ & $63-65$ & $66-68$ & $69-71$ \\
Pinggang & & & & & \\
Lingkar pinggul & $97-71$ & $73-77$ & $79-84$ & $86-91$ & $93-97$ \\
\hline
\end{tabular}

\section{Menentukan Kategori Usia dan Jenis Kelamin}

Kategori usia dikelompokkan menjadi 3 kategori yaitu kategori anak-anak (usia 4 tahun sampai 12 tahun), remaja (usia 13 tahun sampai 17 tahun) dan dewasa (usia diatas 17 tahun). Selanjutnya, untuk jenis kelamin dibagi menjadi dua, yaitu laki-laki dan perempuan. 


\section{Menentukan Data Batik yang Diambil}

Pada penelitian ini, batik Blitar yang digunakan berjumlah 32 jenis motif dengan 70 desain motif dan warna yang berbeda. Batik Blitar yang digunakan sebagai sampel data pada penelitian ini yaitu motif koi, daun lumbu, semen rama, buah kakao, ikan laut, kopi, ukel, parang, anggrek, sido luhur, kipas, wahyu sangkelat, sawunggaling, lung sari, lele, belimbing, nitik jonggrong, kupu-kupu, wahyu tumurun, wijaya kusuma, kawung, cokro kusumo, simbar, kantong semar, sekar arum, daun mint, kontemporer, truntum, dan garuda. Beberapa nama motif batik tersebut memiliki lebih dari satu macam varian desain, ukuran, dan warna batik, seperti motif daun lumbu ada tiga jenis batik yang berbeda desain, warna dan ukuran motif, namun memiliki nama yang sama. Berikut ini beberapa sampel data batik Djojo Koesoemo :

Tabel 3.5 Data Batik Djojo Koesoemo

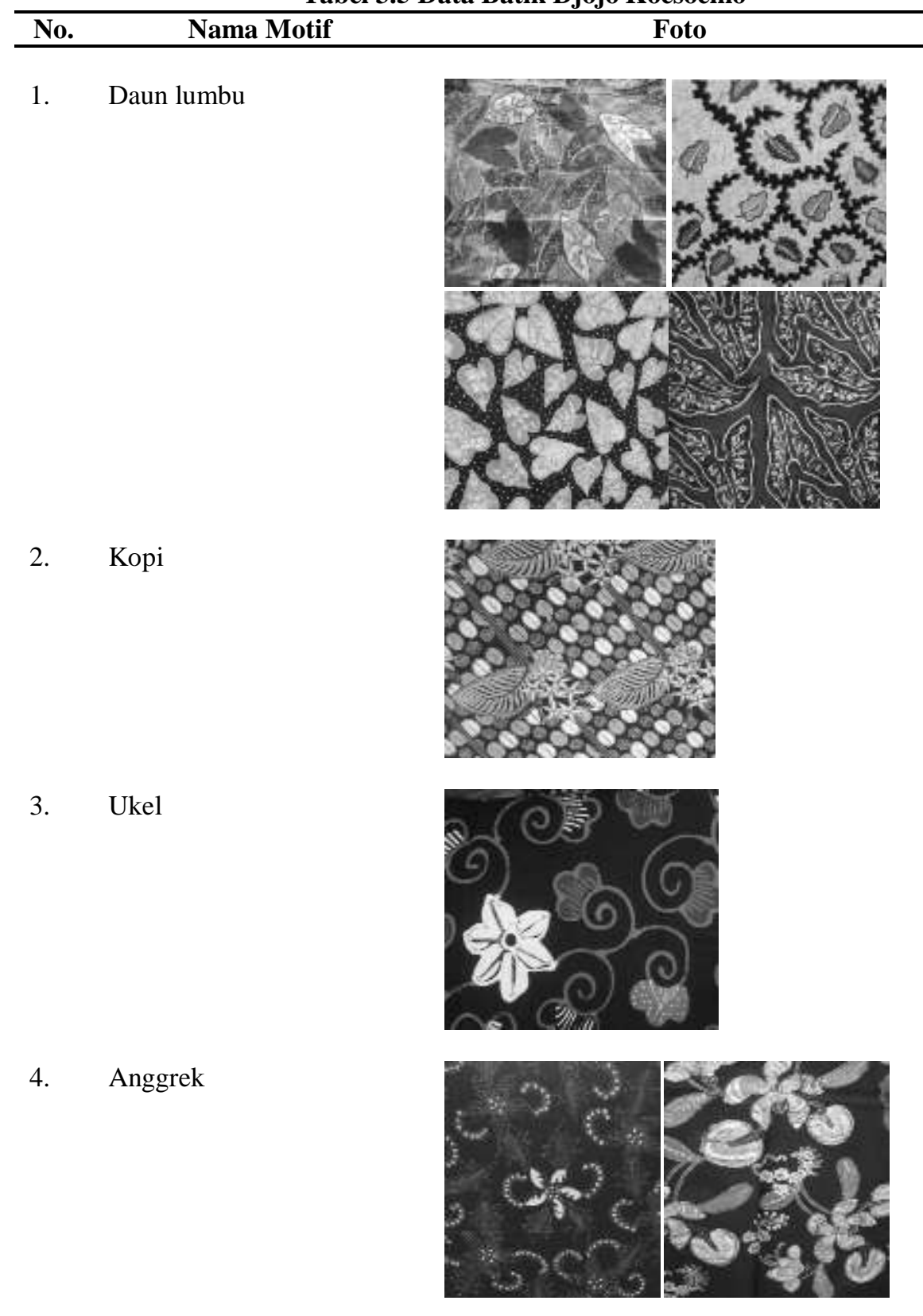


5. Koi

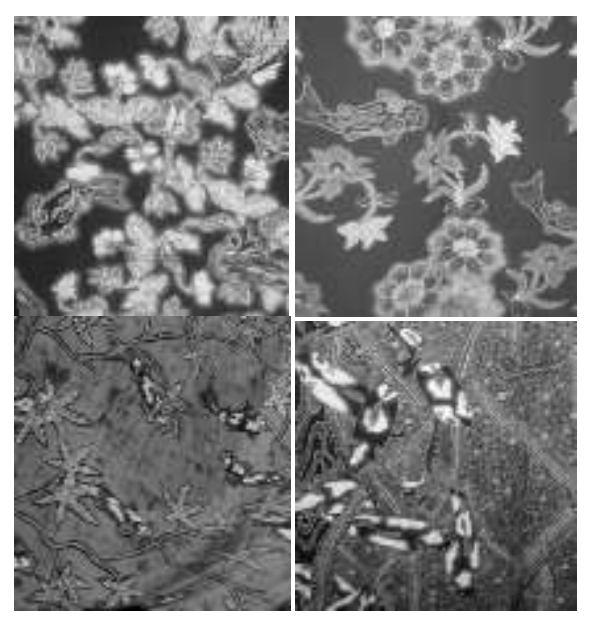

\section{Menentukan Rule Pemilihan Motif dan Warna Batik}

Forward Chaining merupakan metode inferensi yang melakukan penalaran dari suatu masalah kepada solusinya. Metode ini adalah kebalikan dari metode backward chaining, di mana metode ini dijalankan dengan mengumpulkan fakta-fakta yang ada untuk menarik kesimpulan. Operasi dari sistem pakar yang menggunakan Forward Chaining dimulai dengan memasukkan sekumpulan fakta yang diketahui ke dalam memori kerja (working memory), kemudian menurunkan fakta baru berdasarkan aturan yang premisnya cocok dengan fakta yang diketahui (Hayadi, 2016: 11). Selanjutnya, Kusrini (2008: 9) menyebutkan jika klausa premis sesuai dengan situasi (bernilai TRUE), maka proses akan menyatakan konklusi seperti berikut.

Aturan 1 :

Jika premis 1

Dan premis 2

Dan premis 3

Maka konklusi 1

Aturan 2 :

Jika premis 1

Dan premis 3

Dan premis 4

Maka konslusi 2

Aturan 3 :

Jika premis 2

Dan premis 3 
Dan premis 5

Maka konslusi 3,

Aturan $4:$
Jika premis 1
Dan premis 4
Dan premis 5
Dan premis 6
Maka konslusi 4.

Dalam hal ini, syarat yang digunakan sebagai rule untuk memenuhi konklusi memiliki empat premis yaitu premis pertama disebut age (kategori usia), premis kedua adalah gender (jenis kelamin), premis ketiga merupakan kulit (jenis warna kulit) dan premis keempat dinamakan size (ukuran pakaian). Berikut beberapa contoh rule pemilihan motif dan warna batik berdasarkan ciri fisik :

Tabel 3.6 Rule Pemilihan Motif dan Warna Batik

\begin{tabular}{|c|c|}
\hline No. & Rule \\
\hline 1 & $\begin{array}{l}\text { Rule } 1 \text { : } \\
\text { If age anak-anak and gender pria and kulit hitam and size XL or XXL } \\
\text { Then motif belimbing and motif ikan laut }\end{array}$ \\
\hline 2 & $\begin{array}{l}\text { Rule } 2 \text { : } \\
\text { If age anak-anak and gender pria and kulit hitam and size } \mathrm{L} \\
\text { Then motif belimbing and daun lumbu }\end{array}$ \\
\hline 3 & $\begin{array}{l}\text { Rule } 3 \text { : } \\
\text { If age anak-anak and gender pria and kulit hitam and size } \mathrm{S} \text { or } \mathrm{M} \\
\text { Then wahyu sangkelat and motif belimbing }\end{array}$ \\
\hline 4 & $\begin{array}{l}\text { Rule } 4 \text { : } \\
\text { If age remaja and gender pria and kulit hitam and size XL or XXL } \\
\text { Then motif daun lumbu and motif parang }\end{array}$ \\
\hline 5 & $\begin{array}{l}\text { Rule } 5 \text { : } \\
\text { If age remaja and gender pria and kulit putih and size } \mathrm{L} \\
\text { Then motif wahyu sangkelat and motif parang }\end{array}$ \\
\hline
\end{tabular}

\section{E. Pengujian metode black box}

Pengujian program dilakukan untuk mengetahui kesalahan-kesalahan yang ada dan untuk memastikan kebenaran dalam penulisan kode yang terdapat sistem. Black box testing atau pengujian black box merupakan pengujian sistem yang terfokus pada pemenuhan kebutuhan unit program yang disebutkan dalam spesifikasi (Hanif, 2007:316). Pengujian ini dilakukan dengan menjalankan program tersebut, sehingga dapat diketahui apakah sudah memenuhi kebutuhan (requirement) atau tidak. Berikut ini disajikan hasil dari pengujian black box testing.

Tabel 3.7 Pengujian Black Box

\begin{tabular}{lllll}
\hline No. & Skenario & Input & Output & Hasil \\
\hline 1. & Berhasil & Username : 123, & User berhasil & Valid \\
& $\begin{array}{l}\text { melakukan login } \\
\text { sebagai user }\end{array}$ & Password: 08082014 & $\begin{array}{l}\text { mantuk } \\
\text { melakukan }\end{array}$ & \\
\hline
\end{tabular}




\begin{tabular}{|c|c|c|c|c|}
\hline & & & konsultasi & \\
\hline 2. & $\begin{array}{l}\text { Gagal melakukan } \\
\text { login sebagai } \\
\text { user }\end{array}$ & $\begin{array}{l}\text { Username: } \\
\text { 123,Password: } 12345678\end{array}$ & $\begin{array}{l}\text { Muncul tampilan } \\
\text { halaman } \\
\text { peringatan login } \\
\text { gagal }\end{array}$ & $\begin{array}{l}\text { Tidak } \\
\text { valid }\end{array}$ \\
\hline 3. & $\begin{array}{l}\text { Rule } 1 \text { : } \\
\text { If age anak-anak } \\
\text { and gender pria } \\
\text { and kulit hitam } \\
\text { and size XL or } \\
\text { XXL Then motif } \\
\text { belimbing and } \\
\text { motif ikan laut }\end{array}$ & $\begin{array}{l}\text { Kategori usia : anak-anak } \\
\text { Jenis kelamin : pria } \\
\text { Warna kulit : hitam } \\
\text { Ukuran pakaian :XL atau } \\
\text { XXL }\end{array}$ & $\begin{array}{l}\text { Batik yang } \\
\text { direkomendasikan } \\
\text { motif belimbing } \\
\text { dan motif ikan laut }\end{array}$ & Valid \\
\hline 4. & $\begin{array}{l}\text { Rule } 1 \text { : } \\
\text { If age anak-anak } \\
\text { and gender pria } \\
\text { and kulit hitam } \\
\text { and size XL or } \\
\text { XXL } \\
\text { Then motif } \\
\text { belimbing and } \\
\text { motif ikan laut }\end{array}$ & $\begin{array}{l}\text { Kategori usia : remaja } \\
\text { Jenis kelamin : pria } \\
\text { Warna kulit : hitam } \\
\text { Ukuran pakaian : XL atau } \\
\text { XXL }\end{array}$ & $\begin{array}{l}\text { Batik yang } \\
\text { direkomendasikan } \\
\text { motif wahyu } \\
\text { sangkelat dan } \\
\text { motif parang }\end{array}$ & $\begin{array}{l}\text { Tidak } \\
\text { valid }\end{array}$ \\
\hline 5. & $\begin{array}{l}\text { Rule } 2 \text { : } \\
\text { If age anak-anak } \\
\text { and gender pria } \\
\text { and kulit hitam } \\
\text { and size } \mathrm{L} \\
\text { Then motif } \\
\text { belimbing and } \\
\text { daun lumbu }\end{array}$ & $\begin{array}{l}\text { Kategori usia : anak-anak } \\
\text { Jenis kelamin : pria } \\
\text { Warna kulit : hitam } \\
\text { Ukuran pakaian : L }\end{array}$ & $\begin{array}{l}\text { Batik yang } \\
\text { direkomendasikan } \\
\text { motif belimbing } \\
\text { dan daun lumbu }\end{array}$ & Valid \\
\hline 6. & $\begin{array}{l}\text { Rule } 2 \text { : } \\
\text { If age anak-anak } \\
\text { and gender pria } \\
\text { and kulit hitam } \\
\text { and size } \mathrm{L} \\
\text { Then motif } \\
\text { belimbing and } \\
\text { daun lumbu }\end{array}$ & $\begin{array}{l}\text { Kategori usia : anak-anak } \\
\text { Jenis kelamin : pria } \\
\text { Warna kulit : hitam } \\
\text { Ukuran pakaian : S atau } \\
\text { M }\end{array}$ & $\begin{array}{l}\text { Batik yang } \\
\text { direkomendasikan } \\
\text { wahyu sangkelat } \\
\text { dan motif } \\
\text { belimbing }\end{array}$ & $\begin{array}{l}\text { Tidak } \\
\text { valid }\end{array}$ \\
\hline 7. & $\begin{array}{l}\text { Rule } 3 \text { : } \\
\text { If age anak-anak } \\
\text { and gender pria } \\
\text { and kulit hitam } \\
\text { and size } \mathrm{S} \text { or } \mathrm{M} \\
\text { Then wahyu } \\
\text { sangkelat and } \\
\text { motif belimbing }\end{array}$ & $\begin{array}{l}\text { Kategori usia : anak-anak } \\
\text { Jenis kelamin :pria } \\
\text { Warna kulit : hitam } \\
\text { Ukuran pakaian : S atau } \\
\text { M }\end{array}$ & $\begin{array}{l}\text { Batik yang } \\
\text { direkomendasikan } \\
\text { wahyu sangkelat } \\
\text { dan motif } \\
\text { belimbing }\end{array}$ & Valid \\
\hline 8. & $\begin{array}{l}\text { Rule } 3 \text { : } \\
\text { If age anak-anak } \\
\text { and gender pria } \\
\text { and kulit hitam }\end{array}$ & $\begin{array}{l}\text { Kategori usia : remaja } \\
\text { Jenis kelamin : pria } \\
\text { Warna kulit : hitam } \\
\text { Ukuran pakaian }: \mathrm{S} \text { atau }\end{array}$ & $\begin{array}{l}\text { Batik yang } \\
\text { direkomendasikan } \\
\text { motif koi dan } \\
\text { motif wahyu }\end{array}$ & $\begin{array}{l}\text { Tidak } \\
\text { valid }\end{array}$ \\
\hline
\end{tabular}




\begin{tabular}{|c|c|c|c|c|}
\hline & $\begin{array}{l}\text { and size } \mathrm{S} \text { or } \mathrm{M} \\
\text { Then wahyu } \\
\text { sangkelat and } \\
\text { motif belimbing }\end{array}$ & $\mathrm{M}$ & sangkelat & \\
\hline 9. & $\begin{array}{l}\text { Rule } 4 \text { : } \\
\text { If age remaja and } \\
\text { gender pria and } \\
\text { kulit hitam and } \\
\text { size XL or XXL } \\
\text { Then motif daun } \\
\text { lumbu and motif } \\
\text { parang }\end{array}$ & $\begin{array}{l}\text { Kategori usia : remaja } \\
\text { Jenis kelamin : pria } \\
\text { Warna kulit : hitam } \\
\text { Ukuran pakaian : XL atau } \\
\text { XXL }\end{array}$ & $\begin{array}{l}\text { Batik yang } \\
\text { direkomendasikan } \\
\text { motif daun lumbu } \\
\text { dan motif parang }\end{array}$ & Valid \\
\hline 10. & $\begin{array}{l}\text { Rule 5: } \\
\text { If age remaja and } \\
\text { gender pria and } \\
\text { kulit putih and } \\
\text { size L } \\
\text { Then motif wahyu } \\
\text { sangkelat and } \\
\text { motif parang }\end{array}$ & $\begin{array}{l}\text { Kategori usia : remaja } \\
\text { Jenis kelamin : pria } \\
\text { Warna kulit : hitam } \\
\text { Ukuran pakaian : L }\end{array}$ & $\begin{array}{l}\text { Batik yang } \\
\text { direkomendasikan } \\
\text { motif wahyu } \\
\text { sangkelat dan } \\
\text { motif parang }\end{array}$ & Valid \\
\hline
\end{tabular}

Berdasarkan hasil uji coba login dan rule di atas, dapat diketahui bahwa login diuji dengan dua skenario yakni dengan memasukan password dan username yang benar, serta password dan username yang salah yang mana didapatkan hasil valid sebesar 50\% dan tidak valid sebesar 50\%. Kemudian, terdapat delapan pengujian rule untuk mengetahui apakah output sudah sesuai yang diharapkan. Dari delapan pengujian tersebut, lima di antaranya memiliki hasil valid dan sisanya memiliki hasil tidak valid.

Persentase skenario yang valid dibagi dengan jumlah skenario pengujian rule keseluruhan lalu dikali $100 \%$ sehingga menghasilkan persentase skenario valid sebesar $62,5 \%$, sedangkan skenario yang tidak valid dibagi dengan jumlah skenario pengujian rule keseluruhan lalu dikali $100 \%$ sehingga menghasilkan persentase skenario tidak valid sebesar 37,5\%. Selanjutnya, hasil persentase pengujian login dan rule dijumlahkan dan dibagi dua, sehingga hasilnya adalah 56,2\%.

\section{SimPUlan DAN SARAN}

A. Simpulan

Berdasarkan hasil penelitian mengenai sistem pakar penentuan motif dan warna batik berdasarkan ciri fisik, maka dapat diambil kesimpulan sebagai berikut. Pertama, program sistem pakar ini dirancang dan dibuat untuk pengguna dengan cara membentuk 72 aturan (rule) lalu mencocokkannya dengan 70 sampel data batik sebagai rekomendasi yang dimasukkan ke dalam bentuk perulangan if-else. Ketika ingin berkonsultasi, pengguna akan diminta untuk menginputkan jawaban dari beberapa pertanyaan, kemudian masukkan user akan diproses menggunakan metode Forward Chaining yang akan menghasilkan output berupa rekomendasi motif dan warna batik. Jika data input ciri fisik tidak lengkap, maka sistem akan memberikan peringatan untuk melengkapi data karena tanpa kelengkapan data ciri fisik, sistem tidak dapat memberikan rekomendasi. Kedua, pengujian dengan metode black box dilakukan dengan cara membagi nilai valid dengan jumlah pengujian dan dikali $100 \%$. Dari sepuluh pengujian yang terbagi menjadi dua (pengujian login dan rule), mengasilkan persentase valid sebesar 50\% untuk login dan 62,5\% untuk rule yang kemudian dijumlahkan dan dibagi dua, sehingga hasil pengujian keseluruhan adalah sebesar $56,2 \%$. 


\section{B. Saran}

Berdasarkan kesimpulan di atas, peneliti memberikan saran agar program ini dapat dikembangkan dengan menggunakan metode lain misalnya Artificial Neural Network, sehingga sistem dapat memberikan rekomendasi secara otomatis. Selain itu, data batik yang digunakan tidak hanya batik Blitar saja, tetapi juga batik dari daerah lain.

\section{Daftar Pustaka}

Alim, Putra S. 2015. Model Fuzzy Expert System Berbasis Pemakai pada PT. Batik Semar Cabang Medan. Jurnal Buana Informatika. Vol 6. pp 11-20.

Alpha dan Oslan. 2015. Program Bantu Pemilihan Pakaian dan Bahan Batik bagi Konsumen dengan Pendekatan Decission Tree. Jurnal Eksis. Vol 2. pp 37- 46.

Anonym. 2004. Aplikasi Program PHP \& MySQL untuk Membuat Website Interaktif. Yogyakarta: Andi. Arhami, M. 2005. Konsep Dasar Sistem Pakar. Yogyakarta: Andi.

Asti Musman, Ambar B. Arini. 2011. Batik: Warisan Adiluhung Nusantara. Yogyakarta: Andi.

Daryanto. 2004. Memahami Kinerja Internet. Bandung: Yrama Widya.

Dharma dan Sutedjo. 2002. E-Ducation Konsep, Teknologi, dan Aplikasi Internet Pendidikan. Yogyakarta: Andi.

Doellah, S. 2002. Batik: Pengaruh Jaman dan Lingkungan. Solo.

Farizi, Anief. 2014. Sistem Pakar untuk Mendiagnosa Kerusakan Komputer dengan Menggunakan Metode Forward Chaining. Edu Komputika Journal. Vol 1. pp 21-32.

Gustikasari dan Winiarti. 2013. Aplikasi Sistem Pakar Penentuan Perawatan Kecantikan Berbasis Web (studi kasus : Pamella Salon Yogyakarta). Jurnal Sarjana Teknik Informatika Vol 1. pp 563-573. Gustin, dkk. 2013. Sistem Pakar Batik Yogyakarta Berbasis Web. JNTETI. Vol 2. pp 260-267.

Hanif, Al Fatta. 2007. Analisis dan Perancangan Sistem Informasi untuk Keunggulan Bersaing Perusahaan dan Organisasi Modern. Yogyakarta: Andi.

Hayadi, B. Herawan. 2016. What is Expert System. Yogyakarta : Budi Utama.

ISO/TR 10652, 1991. Standard Sizing Systems for Clothes. International Organization for Standardization, Geneva.

Kadir, Abdul. 2008. Dasar Pemrograman Web Dinamis Menggunakan PHP. Yogyakarta : Andi.

Kusrini. 2006. Sistem Pakar, Teori dan Aplikasi. Yogyakarta: Andi. - 2008. Aplikasi Sistem Pakar, Menentukan Faktor Kepastian Pengguna dengan Metode Kuantifikasi Pertanyaan. Yogyakarta: Andi.

Kusumadewi, Sri. 2003. Artificial Intelligence (Teknik dan Aplikasinya). Yogyakarta: Graha Ilmu.

Panji. 2014. Batik Tutur: Batik Tulis Khas Blitar. Media Kita Panji Nusantara (Menegakkan Kedaulatan dengan Budaya). Hal 9.

P. Hetty dan Clara. 2013. Rule Base Expert System dengan Metode Forward Chaining untuk Memprediksi Kualitas Kain Batik. Jurnal Ilmiah Saintikom. Vol 12. pp 177-183

Rafitri, dkk. Penentuan Motif Batik Berdasarkan Karakteristik Pemakai Menggunakan Gabungan Algoritma Nä̈ve Bayes dan Expectation Maximization (EM).

Rosenelly, Rika. 2012. Sistem Pakar Konsep dan Teori. Yogyakarta: Andi.

Sachdeva. 2009. Fitzpatrick Skin Typing:Applications in Dermatology. Indian J. Dermatol Venerol Leprol 75:93-3

Susanto, S.SK. 1980. Seni Kerajinan Batik Indonesia, Balai Penelitian Batik dan Kerajinan, Lembaga Penelitian dan Pendidikan Industri. Jakarta : Departemen Perindustrian Republik Indonesia. 